\title{
The effectiveness and safety of Tai Chi for patients with essential hypertension: study protocol for an open-label single-center randomized controlled trial
}

Yuxi $\mathrm{Li}^{1+}$, Dongling Zhong ${ }^{2+}$, Chao Dong ${ }^{3+}$, Lihong Shi ${ }^{2}$, Yaling Zheng ${ }^{2}$, Yongguo Liu ${ }^{4}$, Qiaoqin Li ${ }^{4}$, Hui Zheng ${ }^{1}$, Juan $\mathrm{Li}^{2^{*}}$ (D), Tianyu Liu ${ }^{5^{*}}$ and Rongjiang Jin ${ }^{2^{*}}$

\begin{abstract}
Background: Evidence showed that Tai Chi may have beneficial effects among hypertensive individuals, although the results are not convincing. We aim to conduct a high-quality clinical trial with 24-h BP measurement to provide robust evidence of Tai Chi for essential hypertension.

Methods: This is an open-label single-center randomized controlled trial with 3 parallel arms. We will compare Tai Chi with walking and waiting-list control. We will recruit 234 hypertensive patients with mild to moderate essential hypertension and randomly assign them to 3 different groups. Participants in Tai Chi group will receive a groupformat Yang style 24-form Tai Chi exercise program, 3 sessions per week for 12 weeks. The walking group will be asked to walk, 3 sessions per week for 12 weeks. The waiting-list group will not receive any interventions and/or exercise training. The primary outcome is the change in average 24-h systolic blood pressure (SBP) between baseline and 12 weeks after randomization. The secondary outcomes include 24-h Diastolic Blood Pressure (DBP), average SBP and average DBP during the daytime and night-time, blood pressure (BP) variability, SBP load and DBP load, circadian rhythm of BP, and morning BP surge, endothelial functional indicators, home measured BP, quality of life, adverse events and so on.

Discussion: We expect findings of this trial will provide important insight into application of Tai Chi as an effective and acceptable method for hypertensive patients. Successful completion of this proposed study will also contribute to promotion of Tai Chi in the community in the future.
\end{abstract}

Trial registration: Clinicaltrials.gov registry: https://linicaltrials.gov/ct2/show/NCT04267471, date: February 12, 2020. Keywords: Hypertension, Tai Chi, Open label, Randomized controlled trials, Protocol

\footnotetext{
* Correspondence: 785939016@qq.com; dizangtianyu@sina.com;

cdzyydxjrj@126.com

${ }^{\dagger}$ Yuxi Li, Dongling Zhong and Chao Dong are joint first authors.

${ }^{2}$ School of Health Preservation and Rehabilitation, Chengdu University of

Traditional Chinese Medicine, Chengdu, China

${ }^{5}$ School of Sports, Chengdu University of Traditional Chinese Medicine, Chengdu, China

Full list of author information is available at the end of the article
}

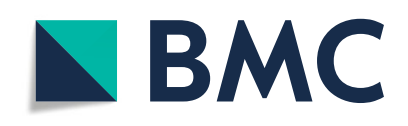

(- The Author(s). 2021 Open Access This article is licensed under a Creative Commons Attribution 4.0 International License, which permits use, sharing, adaptation, distribution and reproduction in any medium or format, as long as you give appropriate credit to the original author(s) and the source, provide a link to the Creative Commons licence, and indicate if changes were made. The images or other third party material in this article are included in the article's Creative Commons licence, unless indicated otherwise in a credit line to the material. If material is not included in the article's Creative Commons licence and your intended use is not permitted by statutory regulation or exceeds the permitted use, you will need to obtain permission directly from the copyright holder. To view a copy of this licence, visit http://creativecommons.org/licenses/by/4.0/. The Creative Commons Public Domain Dedication waiver (http://creativecommons.org/publicdomain/zero/1.0/) applies to the data made available in this article, unless otherwise stated in a credit line to the data. 


\section{Background}

Hypertension is the most common risk factor of stroke and cardiovascular diseases, which accounted for 9.4 million deaths worldwide every year $[1,2]$. The vast majority of instances of high blood pressure pertains to essential hypertension, which is the presence of high blood pressure while there is no detectable medical or organic cause. According to the World Health Organization report, hypertension affects $22 \%$ of adult population around the world [3], and studies showed that the number of hypertensive patients was still increasing [4]. A national wide hypertension survey from 2012 to 2015 reported that the prevalence of hypertension among Chinese population was $23.2 \%$ (estimated 244.5 millions people) [5]. Even so, the control rate of hypertension is quite poor. A crosssectional study of 57,840 hypertensive patients from 17 countries showed that the awareness rate of hypertension was $46.5 \%$, merely $41 \%$ received treatment, and only $13.2 \%$ had blood pressure (BP) under controll [6]. Pharmacological therapies are the mainstream treatment for hypertension. However, Cochrane reviews showed that many patients discontinued treatment due to undesirable adverse effects $[7,8]$.

Evidence showed that regular physical exercise had protective effects on hypertensive individuals [9]. Aerobic activity has been recommended to hypertensive patients by Canadian Hypertension Education Program (CHEP), Eighth Joint National Committee (JNC-8), and American Heart Association (AHA) [10-12]. Tai Chi, a traditional mind-body Chinese exercise, is an aerobic exercise with moderate exercise intensity [13]. It combines deep-breath relaxation and gentle movements in sequence with mind concentration. A number of clinical trials reported that Tai Chi not only had positive effects in healthy population [14-17], it could also improve people's pathological conditions, including Parkinson's disease [18], fibromyalgia [19] and knee osteoarthritis [20].

Several clinical studies reported that Tai Chi may have some benefits in reducing $\mathrm{BP}$ and improving quality of life in hypertensive patients [21-27]. We conducted a systematic review of the existing trials of Tai Chi for essential hypertension [28]. However, we found high heterogeneity and poor methodological quality in these studies, which decreased the liability of evidence. Therefore, we will conduct this randomized controlled trial (RCT) aiming at: first, confirming whether Tai Chi is efficacious for patients with essential hypertension; second, observing the short- and long-term effect of Tai Chi; third, investigating the influence of Tai Chi on endothelial function. In addition, we intend to use 24-h $\mathrm{BP}$ measurement to monitor patients' BP, so as to observe the changes more accurately. In order to provide high quality of evidence, we will conduct this trial in line with Standard Protocol Items: Recommendations for Interventional Trials (SPIRIT) [29] and report our findings in accordance with the Consolidated Standards of Reporting Trial (CONSORT) statement [30]. This clinical trial is registered with an identifier (NCT04267471) at clinicaltrials.gov in February 2020.

\section{Methods/design}

\section{Design and setting}

This is an open-label single-center RCT with 3 parallel arms. This trial has been approved by the regional ethical review committee of traditional Chinese medicine in Sichuan Province in March 2019 (reference number: 2019KL-001). We will compare Tai Chi with walking and waiting-list control. The trial will be conducted in the Hospital of Chengdu University of Traditional Chinese Medicine. The whole study period is 25 weeks, with 1 -week baseline, 12-week intervention phase and 12-week follow-up phase. After randomization, participants in Tai Chi group and walking group will receive exercise training 3 times per week for continuous 12 weeks. Participants in waiting-list group can decide whether or not to receive exercise training after follow-up period. Outcomes will be measured at baseline, 12 weeks and 24 weeks after randomization. All participants will be required to sign the written informed consent before randomization. This protocol was compiled in line with the SPIRIT 2013 [29] (Table 1). The flow diagram of this trial is presented in Fig. 1.

\section{Participants \\ Sample size}

This study is an RCT, the intervention group is the Tai Chi group, and the control groups are walking group and waiting-list group. The reduction of Systolic Blood Pressure (SBP) is set as the primary outcome. According to previous study [31], the mean difference and standard deviation of SBP was $-13.33 \pm 46.73,-12.46 \pm 33.37$ and $3.37 \pm 46.01$ for Tai Chi compared with walking and waiting-list control. The sample size was calculated using One-Way analysis of variance, F-Tests with the PASS 15.0 software. The standard deviation is set as 20 . A total of 65 participants per arm are needed to achieve a power of $80 \%$ at a significant level of $5 \%$. A sample size of 195 participants is required to sufficiently detect a target effect size. Considering a $20 \%$ drop-out rate, we intend to enroll a total of 234 participants, with 78 participants in each group.

\section{Recruitment}

Participants will be recruited by posters, doctor's recommendation, internet and WeChat in Chengdu city. If participants meet the study criteria, they will be 
Table 1 A standard protocol items: recommendation for interventions for trials (SPIRIT)

\begin{tabular}{|c|c|c|c|c|}
\hline \multirow[t]{2}{*}{ Items } & \multirow{2}{*}{$\begin{array}{l}\text { Run-in period } \\
-1 \text { st week }\end{array}$} & \multicolumn{2}{|c|}{ Intervention period } & \multirow{2}{*}{$\begin{array}{l}\text { Follow-up period } \\
\text { 24th week }\end{array}$} \\
\hline & & 1st week & 12th week & \\
\hline \multicolumn{5}{|l|}{ Patients } \\
\hline Informed consent & $x$ & & & \\
\hline In/exclusion criteria & $x$ & & & \\
\hline Randomization and allocation & $x$ & & & \\
\hline \multicolumn{5}{|l|}{ Intervention } \\
\hline \multicolumn{5}{|l|}{ Tai Chi group } \\
\hline \multicolumn{5}{|l|}{ Walking group } \\
\hline \multicolumn{5}{|l|}{ Waiting-list group } \\
\hline \multicolumn{5}{|l|}{ Outcomes } \\
\hline 24-h BP & $\times$ & & $x$ & $x$ \\
\hline Serum proportion of NO、ET、TXA2、VEGF & $x$ & & $x$ & \\
\hline BP measured at home & $x$ & $x$ & $x$ & $x$ \\
\hline SF-36 & $x$ & & $x$ & \\
\hline \multicolumn{5}{|l|}{ Safety } \\
\hline Adverse events & & $x$ & $x$ & $x$ \\
\hline Reasons drop-out and withdrawals & & $x$ & $x$ & $x$ \\
\hline
\end{tabular}

BP Blood pressure, NO Nitric Oxide, ET Endothelin, TXA2 Thromboxane A2, VEGF Vascular endothelial growth factor, SF-36 Medical Outcomes Study 36-Item Short Form

required to sign informed consent form prior to inclusion of the study.

\section{Diagnostic criteria}

According to the 2010 Chinese Guidelines for the Management of Hypertension [32], patients with $\mathrm{SBP} \geq 140 \mathrm{mmHg}$ and/or Diastolic Blood Pressure (DBP) $\geq 90 \mathrm{mmHg}$ without using antihypertensive drugs for 3 times on different days are diagnosed with hypertension. The patient who has a history of hypertension and is currently using antihypertensive drugs with BP below 140/90 $\mathrm{mmHg}$ is also diagnosed with hypertension. All patients will be diagnosed by 2-3 cardiovascular physicians with more than 10 years of experience.

\section{Inclusion criteria}

Patients who fulfill all the following inclusion criteria will be included in this study:

(1) aged between 45 to 80 years;

(2) diagnosed with mild to moderate essential hypertension, and meet the diagnostic criteria of mild to moderate essential hypertension according to 2010 Chinese Guidelines for the Management of Hypertension (140 $\mathrm{mmHg} \leq \mathrm{SBP} \leq 169 \mathrm{mmHg}$ and/or $90 \mathrm{mmHg} \leq \mathrm{DBP} \leq 109 \mathrm{mmHg})$ [31];

(3) with or without antihypertensive medication;

(4) with no regular exercise in the past 3 months;

(5) willing to comply with the study protocol;

(6) willing to sign informed consent form. 


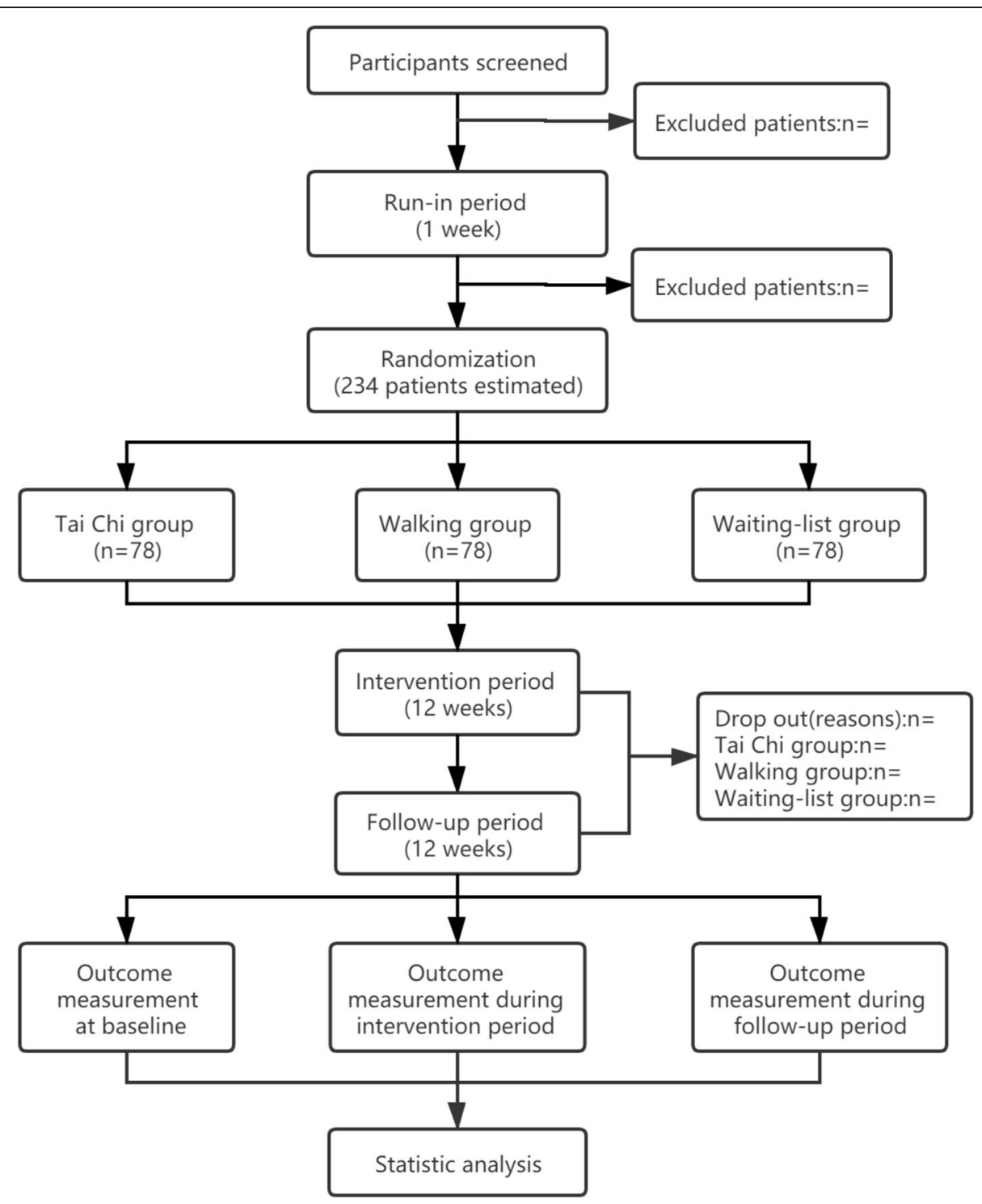

Fig. 1 Flow diagram of study design

\section{Exclusion criteria}

Patients with one of the following criteria will be excluded:

(1) diagnosed with secondary hypertension or refractory hypertension [33];

(2) with severe medical visceral condition and chronic diseases, such as diabetes, epilepsy, severe depression or anxiety, psychosis;

(3) with severe bone and joint diseases or motor dysfunction limit ability to participant exercise;

(4) with severe cognitive decline (Montreal Cognitive Assessment, MoCA [34], <26)

(5) with decreased myodynamia, poor balance or limited vision that would impede full participation in the study;

(6) participated in other clinical trials at the same time.

\section{Allocation and randomization}

Included participants will be randomly assigned to 3 groups (Tai Chi group, walking group, and waiting-list group) with 1:1:1 ratio. The randomization sequence will be created using $\mathrm{R} 3.5 .1$ by an independent statistician. The information of random numbers, allocation and intervention will be packed in opaque envelopes, and will be concealed to screeners and outcome assessors. A research assistant will inform eligible participants the allocation results through phone call after opening envelopes in order.

\section{Blinding}

Due to the nature of Tai Chi, participants and researchers are impossible to be blinded to the group assignment. To minimize bias, all outcomes will be measured at baseline, 
12 weeks and 24 weeks after randomization by the same independent experienced assessors who are blinded to the allocation. After completing the statistical analyses, the group assignment will be revealed by the project manager.

\section{Withdrawal criteria and management}

Participants will be allowed or required to withdraw from the trial if:

(1) participants developing a serious disease which is not suitable to continue in the investigator's opinion;

(2) seriously adverse events happen;

(3) participants request to withdraw from the trial.

The reasons and exit time will be recorded in standard case report forms (CRF).

\section{Interventions}

All participants will be asked to maintain usual diet and lifestyle. We will use CRF to record session attendance of participants in Tai Chi group and walking group. In order to monitor the progress, we will collect and analyze the session attendance as well as the selfreported diaries.

\section{Tai Chi exercise}

Participants in Tai Chi group will be firstly instructed Yang style 24-form Tai Chi by the coaches with at least 5 years of teaching experience during the run-in period. After 3 days of teaching, coaches will assess the qualification of each participants based on: (1) accuracy of movement; (2) coordination and continuity of movement; (3) pauses times. Participants whose fluency and accuracy of Tai Chi movement reach over $60 \%$ with less than 5 times of pauses will be considered to be qualified. Unqualified patients will continue a 3-day teaching and a secondary evaluation. During the intervention period, qualified participants will receive a group-format exercise program, 3 sessions per week for 12 weeks. Each session will last $60 \mathrm{~min}$, including a 10 -min warm-up, a 40-min Tai Chi practice and a 10-min cool-down.

\section{Walking exercise}

Using aerobic exercise to reduces BP has been confirmed [35, 36] and recommended in hypertension management guidelines [32, 37]. Walking is a simple and easy aerobic exercise for the elderly to do. We will use walking with targeted intensity as an active controlled. Walking group will be asked to walk, 3 sessions per week for 12 weeks. Each session will last $60 \mathrm{~min}$, including a 10-min warm-up, a 40-min walking and a 10-min cool-down. To ensure the compliance of exercise, participants will be asked to record the start and end time of each exercise session in self-reported diaries.

\section{Exercise intensity of Tai Chi and walking}

Studies showed that Tai Chi is an aerobic exercise with moderate intensity $[13,38,39]$. In order to achieve the comparability of Tai Chi group and walking group, we will use fitness tracker (HUAWEI HONOR 3, HUAWEI TECHNOLOGIES CO., LTD., China) to record participants' heart rate during exercises to estimate exercise intensity in accordance with the definition of American College of Sports Medicine of moderate intensity aerobic exercise [40]. The target intensity is $64-76 \%$ of maximal heart rate (220-the person's age). To ensure that participants in Tai Chi group and walking group exercised with the intended intensity throughout the training period, exercise intensity will be calculated and adjusted for 3 times during intervention periods (between weeks 1 to 4 , 4 to 8 , and 8 to 12 ).

\section{Waiting list}

Participants in waiting-list group will not receive any interventions and/or exercise training during the intervention period. They will give an option to receive Tai Chi training after follow-up period.

\section{Baseline assessment}

The participants will undergo baseline assessment before intervention. A descriptive exploratory questionnaire will be administered to collect information as follows: (1) demographic and socioeconomic variables (gender, age, socioeconomic status, and education); (2) behavioral variables (physical activity, smoking, and alcohol consumption); (3) anthropometric variables (bodyweight, height, and waist circumference); (4) clinical variables (endothelial function and clinic BP).

\section{Outcome measurements Primary outcome}

The primary outcome in our study is the change in average 24-h SBP between baseline and 12-week after randomization. Ambulatory blood pressure monitoring (ABPM) will be used to assess the BP level. Participants will wear ABPM kit (Space Labs Medical, ABP Monitor 90,217, Redmond, WA, USA) and maintain their usual activities during the monitoring period, while avoiding strenuous exercise. During a 24-h monitoring period, automatic inflation measurement will be taken every 15 min during daytime (07:00 to $22: 59)$ and every $30 \mathrm{~min}$ during night-time (22:59 to 07:00). The 24-h ABPM will be measured at baseline, 12 weeks and 24 weeks after randomization. Participants will be asked to record the time to wake up and go to bed in their self-dairies. 


\section{Secondary outcomes}

The average 24-h DBP, average SBP and average DBP during the daytime and night-time, BP variability, SBP load and DBP load, circadian rhythm of BP, and morning $\mathrm{BP}$ surge measured by ABPM will be considered as secondary outcomes.

Endothelial dysfunction is associated with hypertension and its presence correlates with target organ damage. Furthermore, endothelial dysfunction may be both a cause and a consequence of hypertension [41]. Therefore, the change of serum concentrations of Nitric Oxide (NO), endothelin (ET), thromboxane A2(TXA2), vascular endothelial growth factor (VEGF) will be tested to measure the endothelial function using commercial ELISA kits (Bender MedSystems, Vienna, Austria). Blood samples of participants will be collected at baseline and 12 weeks after randomization.

Home blood pressure monitoring (HBPM) is a selfmonitoring tool that can be incorporated into the care for patients with hypertension. Patients will use automated blood pressure monitors (AND, UA-767PBT; Shenzhen, China) to measure BP at home. HBPM will be conducted according to 2019 Chinese Hypertension League guidelines on home blood pressure monitoring [42] during the whole trial. At baseline, patients will measure BP at home every morning (6:00-9:00) and evening (18:00-21:00), 3 times per measurement for 7 days. During intervention and follow-up, patients will measure BP at home every Monday morning (6:00-9:00) and evening (18,00-21:00), 3 times per measurement [42]. Meanwhile, participants will be asked to record BP value in their self-dairies.

Changes in patients' health-related quality of life will also be assessed according to the Medical Outcomes Study 36-Item Short Form (SF-36) questionnaire Chinese version [43]. This scale contains eight dimensions (physical function, role physical, bodily pain, general health, vitality, social function, role emotional, mental health) and two summary components (physical and mental), with score from 0 to 100 . High scores indicate a better quality of life. SF-36 will be measured at baseline and 12 weeks after randomization.

For participants with antihypertensive medication, they will be asked to record the frequency, dosage and types of medication in their self-dairies.

\section{Attendance and drop-outs}

The attendance of each participants will be checked and recorded in the CRF. Drop-outs from causes such as house moving, onset of severe diseases, or other medical complications are unavoidable, all the details will be recorded in the CRF.

\section{Safety monitoring}

Adverse events are defined as any unexpected or uncomfortable signs, symptoms, or diseases. These adverse events include falling, fainting and any injury related to exercise. If any adverse events happen during the entire observation period, all the details will be recorded in the CRF.

\section{Data collection and management}

All data will be collected and managed using the Research electronic data capture (REDCap) system [44]. The data will be entered into the REDCap Database by a dependent researcher, then double checked by a second researcher. The statistician will review the database to ensure accurate data collection and correct data export for future analyses. All data will either be kept in a secure and lock-protected location and be backed up in different network drives.

\section{Investigator training and quality control}

We will hold expert consultation meetings to formulate Standard Operating Procedure (SOP) of this study. After that all researchers involved in this study will receive theoretical and practical training courses based on SOP to ensure this trial completely standardized. The training will include how to screen the eligible participants, instruct participants to complete the diary, complete the CRF and assess SF-36 and safety. To ensure the highquality of this study, quality control assessment will be carried out every month. A specially trained medical officer will inspect the study.

\section{Statistical analysis}

The statistical analysis will be carried out using SPSS statistical package (version 25.0). Data will expressed as mean \pm standard deviations. All primary and secondary analyses will be analyzed based on intention-to-treat. Missing data will be filled by Last Observation Carry Forward rules. Demographic characteristics and other baseline values will be described using descriptive statistics. Baseline characteristics of participants will be compared using chi-square test for enumeration data and one-way analysis of variance for continuous variables. For the primary outcome, we will run a comparison between Tai Chi group, walking group and waiting list control group to figure out whether exercise is more effective for this condition. We will then run another comparison between Tai Chi group and walking group to figure out whether Tai Chi is more efficacious for hypertension. The above analysis will be performed using the ANCOVA model, age, pre-intervention BP, duration of hypertension, and family history of hypertension will be used as covariate [45]. Difference between the groups was calculated as mean differences or odds ratios 
alongside with their 95\% confidence intervals. Multiple comparisons between the groups will be adjusted according to the Bonferroni correction method. The correlational analysis of $\mathrm{BP}$ and endothelial function factors will be conducted using Chi-square test. We will perform subgroup analyses based on whether patients are on antihypertensive medication to separate the effect size of Tai Chi.

\section{Patient and public involvement}

No patient has been involved in the design, conception and conduction of this trial. All participants are expected to complete the trial by September 2022.

\section{Ethics and dissemination}

This trial will be conducted according to the principles of the Declaration of Helsinki, which has been approved by the regional ethical review committee of traditional Chinese medicine in Sichuan Province in March 2019 (reference number: 2019KL-001). If there is any modification to the protocol which may impact on the conduction of this study, potential benefit of the patient or may affect patient safety, we will draft a formal amendment to the ethical review committee for approval prior to implementation. This clinical trial is also registered with an identifier (NCT04267471) at clinicaltrials.gov in February 2020. Risks and benefits will be explained clearly to the participants, and they will be given enough time to ask questions and decide whether they will participate this trial. The authors intend to publish the findings of the study in peer-reviewed journals.

\section{Discussion}

In our previous systematic review of Tai Chi for hypertension, we found high heterogeneity and poor methodological quality in original RCTs [28]. Among the included trials, only a few trials reported the results of follow-up, the long-term effect of Tai Chi is unclear. Based on the above facts, we hypothesized that: Tai Chi is superior to waiting-list control and walking control in regulating $\mathrm{BP}$ of patients with essential hypertension. To test the hypothesis, we designed this trial with a waitinglist group as a blank control group, which will provide an untreated comparison for the Tai Chi group to determine whether it is effective. We will use walking with targeted intensity as active-control group. By comparing with the walking group, whether Tai Chi is better than active control in hypertensive patients will be determined. Our previous study found that intervention of Tai Chi for 12-24 weeks could significantly lower SBP and DBP than intervention $<12$ weeks and intervention $>24$ weeks [28]. Therefore, we planned 12 weeks of intervention period to determine the effect of Tai Chi.

Existing studies shows that endothelial dysfunction plays an important role in the development of hypertension [46-48]. Regulating endothelial dysfunction has become a significant therapeutic target of hypertension [41, 46, 49]. Aerobic exercise is found to improve endothelial function in hypertensive patients $[50,51]$. We assume that Tai Chi reduce BP by regulating endothelial function. Hence, we will additionally investigate the correlation between Tai Chi and endothelial function. In order to achieve high reliability and reproducibility of the results, we will implement more stringent quality control standards. To improve the baseline consistency of participants, we will strictly follow the inclusion and exclusion criteria for participant enrollment. Before formal intervention, included participants will receive standardized Tai Chi training and qualification assessment by experienced coaches to ensure the standardization of Tai Chi movements. During the intervention, we will use fitness tracker to monitor the heart rate of participants to make sure they achieve the target exercise intensity. As for measurement, researchers, Tai Chi coaches and outcome assessors will be separated during the study period. Allocation of participants will be concealed to outcome assessors and data analysts. All researchers will conduct this trial in accordance with SOP. Monthly quality control assessment will be performed to ensure research quality.

We hope the findings of this trial will provide important insight into application of Tai Chi as an effective and acceptable method for hypertensive patients. Successful completion of this proposed study will also contribute to promotion of Tai Chi in the community in the future.

\section{Abbreviations}

BP: Blood pressure; CHEP: Canadian Hypertension Education Program; JNC: Joint National Committee; AHA: American Heart Association; SPIR IT: Standard Protocol Items: Recommendations for Interventional Trials; CONSORT: Consolidated Standards of Reporting Trial; SBP: Systolic Blood Pressure; DBP: Diastolic Blood Pressure; CRF: Case report forms; ABPM: Ambulatory blood pressure monitoring; HBPM: Home blood pressure monitoring; SOP: Standard Operating Procedure; SF-36: Medical Outcomes Study 36-Item Short Form

\section{Acknowledgments}

Not applicable.

\section{Authors' contributions}

$J \mathrm{~L}$, TYL and RJJ designed the study. YXL and CD drafted the manuscript. LHS, YLZ and YGL carried out the statistical calculation. DLZ, QQL and HZ revised the manuscript. All authors have read and approved the manuscript.

\section{Funding}

This study was supported by National Key Research and Development Project of China (grant number 2019YFC1710302) and Sichuan Provincial Health and Science Research Project of Sichuan Provincial Health Committee (grant number 19PJ034). The funders had no role in study design, decision to publish or preparation of the manuscript.

\section{Availability of data and materials}

The datasets used and/or analyzed after completing the current study will be available from the corresponding author by reasonable requests. 


\section{Ethics approval and consent to participate}

This trial was approved by the Medical Ethics Committee of Affiliated Hospital of Chengdu University of traditional Chinese Medicine, which belongs to Regional Ethical Review Committee of Traditional Chinese Medicine in Sichuan province (reference number: 2019KL-001). Written informed consent will be obtained from all participants. All procedures in the study are in accordance with the declaration of Helsinki. The authors intend to publish the findings of the study in peer-reviewed journals.

\section{Consent for publication}

Not applicable.

\section{Competing interests}

The authors declare that they have no competing interests. This study protocol has undergone peer-review by the funding body.

\section{Author details}

${ }^{1}$ School of Acupuncture-Moxibustion and Tuina, Chengdu University of Traditional Chinese Medicine, Chengdu, China. ${ }^{2}$ School of Health Preservation and Rehabilitation, Chengdu University of Traditional Chinese Medicine, Chengdu, China. ${ }^{3}$ The General Hospital of Western Theater Command, Chengdu, China. ${ }^{4}$ Knowledge and Data Engineering Laboratory of Chinese Medicine, School of Information and Software Engineering, University of Electronic Science and Technology of China, Chengdu, China. ${ }^{5}$ School of Sports, Chengdu University of Traditional Chinese Medicine, Chengdu, China.

Received: 4 March 2020 Accepted: 15 December 2020

Published online: 07 January 2021

\section{References}

1. WHO. Global NCD target: reduce high blood pressure. Geneva: World Health Organization; 2016.

2. WHO. A global brief on hypertension: silent killer, global public health crisis: World Health Day 2013. Geneva: World Health Organization; 2013.

3. WHO. Hypertension prevelance by $\mathrm{WHO}$ region. Available from: https:// www.who.int/images/default-source/infographics/ncds/prevalence. jpg?sfvrsn=3472e76c_2. Accessed 18 Feb 2020.

4. Wang JG, Li Y. Characteristics of hypertension in the Chinese population Curr Hypertens Rep. 2012;14(5):410-5.

5. Wang Z, Chen Z, Zhang L, Wang X, Hao G, Zhang Z, Shao L, Tian Y, Dong Y, Zheng C, Wang J, Zhu M, Weintraub WS, Gao R, China Hypertension Survey Investigators. Status of hypertension in China: results from the China hypertension survey, 2012-2015. Circulation. 2018;137(22):2344-56.

6. Chow KC. Prevalence, awareness, treatment, and control of hypertension in rural and urban communities in high-, middle-, and low-income countries. JAMA. 2013:310(9):959.

7. Guirguis-Blake J. Pharmacotherapy for mild hypertension. Am Fam Physician. 2013:88(1):21.

8. Musini VM, Tejani AM, Bassett K, Puil L, Wright JM. Pharmacotherapy for hypertension in adults 60 years or older. Cochrane Database Syst Rev. 2019; 6(6):CD000028.

9. Engström G, Hedblad B, Janzon L. Hypertensive men who exercise regularly have lower rate of cardiovascular mortality. J Hypertens. 1999;17(6):737-42.

10. James PA, Oparil S, Carter BL, Cushman WC, Dennison-Himmelfarb C, Handler J, Lackland DT, LeFevre ML, MacKenzie TD, Ogedegbe O, Smith SC Jr, Svetkey LP, Taler SJ, Townsend RR, Wright JT Jr, Narva AS, Ortiz E. 2014 evidence-based guideline for the management of high blood pressure in adults: report from the panel members appointed to the Eighth Joint National Committee (JNC 8). JAMA. 2014;311(5):507-20.

11. Hasan SS, Clavarino AM, Dingle K, Mamun AA, Kairuz T. Psychological health and the risk of diabetes mellitus in Australian women: a 21-year prospective study. J Women's Health (Larchmt). 2014;23(11):912-9.

12. Brook RD, Appel $\sqcup$, Rubenfire M, Ogedegbe G, Bisognano JD, Elliott WJ, Fuchs FD, Hughes JW, Lackland DT, Staffileno BA, Townsend RR, Rajagopalan S, American Heart Association Professional Education Committee of the Council for High Blood Pressure Research, Council on Cardiovascular and Stroke Nursing, Council on Epidemiology and Prevention, and Council on Nutrition, Physical Activity. Beyond medications and diet: alternative approaches to lowering blood pressure: a scientific statement from the american heart association. Hypertension. 2013;61(6): 1360-83.

13. Lan C, Chen SY, Lai JS, Wong MK. Heart rate responses and oxygen consumption during Tai Chi Chuan practice. Am J Chin Med. 2001;29(3-4): 403-10.

14. Li F, Harmer P, Eckstrom E, Fitzgerald K, Chou LS, Liu Y. Effectiveness of Tai Ji Quan vs multimodal and stretching exercise interventions for reducing injurious falls in older adults at high risk of falling: follow-up analysis of a randomized clinical trial. JAMA Netw Open. 2019;2(2):e188280.

15. Lee MS, Chan A, Lee A, Suen L, Tam W. Tai chi qigong may improve healthrelated QoL in chronic obstructive pulmonary disease patients. Focus Altern Complement Ther. 2011;16:68-9.

16. Wang F, Lee EK, Wu T, Benson H, Fricchione G, Wang W, Yeung AS. The effects of tai chi on depression, anxiety, and psychological well-being: a systematic review and meta-analysis. Int J Behav Med. 2014;21(4):605-17.

17. Zhong D, Xiao Q, Xiao X, Li Y, Ye J, Xia L, Zhang C, Li J, Zheng H, Jin R. Tai Chi for improving balance and reducing falls: an overview of 14 systematic reviews. Ann Phys Rehabil Med. 2020;63(6):505-17.

18. Li F, Harmer P, Fitzgerald K, Eckstrom E, Stock R, Galver J, Maddalozzo G Batya SS. Tai chi and postural stability in patients with Parkinson's disease. N Engl J Med. 2012;366(6):511-9.

19. Wang C, Schmid CH, Fielding RA, Harvey WF, Reid KF, Price LL, Driban JB, Kalish R, Rones R, McAlindon T. Effect of tai chi versus aerobic exercise for fibromyalgia: comparative effectiveness randomized controlled trial. BMJ. 2018:360:k851.

20. Wang C, Schmid CH, Iversen MD, Harvey WF, Fielding RA, Driban JB, Price $L L$, Wong JB, Reid KF, Rones R, McAlindon T. Comparative effectiveness of Tai Chi versus physical therapy for knee osteoarthritis: a randomized trial. Ann Intern Med. 2016;165(2):77-86.

21. Lo HM, Yeh CY, Chang SC, Sung HC, Smith GD. A Tai Chi exercise programme improved exercise behaviour and reduced blood pressure in outpatients with hypertension. Int J Nurs Pract. 2012;18(6):545-51.

22. Ma C, Wei Z, Qiubo T, Shuling H. The impact of group-based Tai chi on health-status outcomes among community-dwelling older adults with hypertension. Heart Lung J Crit Care. 2018;47(4):337-44.

23. Yeh GY, Wang C, Wayne PM, Phillips RS. The effect of Tai Chi exercise on blood pressure: a systematic review. Prev Cardiol. 2008;11(2):82-9.

24. Wang C, Collet JP, Lau J. The effect of Tai Chi on health outcomes in patients with chronic conditions. ACC Curr J Rev. 2004;13(5):12-3.

25. Lin CL, Lin CP, Lien SYA. The effect of tai chi for blood pressure, blood sugar, blood lipid control for patients with chronic diseases: a systematic review. Hu Li Za Zhi. 2013;60(1):69-77.

26. Zhang D. Clinical effect of 24-style Tai Chi on elderly patients with essential hypertension. Chengdu: Chengdu University of Traditional Chinese Medicine; 2017.

27. Sun J, Buys N. Community-based mind-body meditative tai chi program and its effects on improvement of blood pressure, weight, renal function, serum lipoprotein, and quality of life in Chinese adults with hypertension. Am J Cardiol. 2015;116(7):1076-81.

28. Zhong D, Li J, Yang H, Li Y, Huang Y, Xiao Q, Liu T, Jin R. Tai Chi for essential hypertension: a systematic review of randomized controlled trials. Curr Hypertens Rep. 2020;22(3):25.

29. Chan AW, Tetzlaff JM, Gøtzsche PC, Altman DG, Mann H, Berlin JA, Dickersin K, Hróbjartsson A, Schulz KF, Parulekar WR, Krleza-Jeric K, Laupacis A, Moher D. SPIRIT 2013 explanation and elaboration: guidance for protocols of clinical trials. BMJ. 2013;346:e7586.

30. Schulz KF, Altman DG, Moher D, the CG. CONSORT 2010 Statement: updated guidelines for reporting parallel group randomised trials. BMC Med. 2010;8(1):18.

31. Chan AWK, Chair SY, Lee DTF, Leung DYP, Sit JWH, Cheng HY, Taylor-Piliae RE. Tai Chi exercise is more effective than brisk walking in reducing cardiovascular disease risk factors among adults with hypertension: a randomised controlled trial. Int J Nurs Stud. 2018;88:44-52.

32. Writing Group of 2010 Chinese Guidelines for the Management of Hypertension. 2010 Chinese guidelines for the management of hypertension. Chin J Cardiovasc Dis. 2011;39(7):579-615.

33. Williams B, Mancia G, Spiering W, Agabiti Rosei E, Azizi M, Burnier M, Clement DL, Coca A, de Simone G, Dominiczak A, Kahan T, Mahfoud F, Redon J, Ruilope L, Zanchetti A, Kerins M, Kjeldsen SE, Kreutz R, Laurent S, Lip GYH, McManus R, Narkiewicz K, Ruschitzka F, Schmieder RE, Shlyakhto E, Tsioufis C, Aboyans V, Desormais I, Authors/Task Force Members. 2018 ESC/ 
ESH guidelines for the management of arterial hypertension: the task force for the management of arterial hypertension of the European Society of Cardiology and the European Society of Hypertension: the task force for the management of arterial hypertension of the European Society of Cardiology and the European Society of Hypertension. J Hypertens. 2018;36(10):1953-2041.

34. Nasreddine ZS, Phillips NA, Bédirian V, Charbonneau S, Whitehead V, Collin I, Cummings JL, Chertkow H. The Montreal Cognitive Assessment, MoCA: a brief screening tool for mild cognitive impairment. J Am Geriatr Soc. 2005; 53(4):695-9.

35. Whelton SP, Chin A, Xin X, He J. Effect of aerobic exercise on blood pressure: a meta-analysis of randomized, controlled trials. Ann Intern Med. 2002:136(7):493-503.

36. Martin JE, Dubbert PM, Cushman WC. Controlled trial of aerobic exercise in hypertension. Circulation. 1990;81(5):1560-7.

37. Whelton PK, Carey RM, Aronow WS, Casey DE Jr, Collins KJ, Dennison Himmelfarb C, DePalma SM, Gidding S, Jamerson KA, Jones DW, MacLaughlin EJ, Muntner P, Ovbiagele B, Smith SC Jr, Spencer CC, Stafford RS, Taler SJ, Thomas RJ, Williams KA Sr, Williamson JD, Wright JT Jr. 2017 ACC/AHA/AAPA/ABC/ACPM/AGS/APhA/ASH/ASPC/NMA/PCNA guideline for the prevention, detection, evaluation, and management of high blood pressure in adults: a report of the American College of Cardiology/American Heart Association Task Force on Clinical Practice Guidelines. Hypertension. 2018;71(6):e13-e115.

38. Garber CE, Blissmer B, Deschenes MR, Franklin BA, Lamonte MJ, Lee IM, Nieman DC, Swain DP, American College of Sports Medicine. American College of Sports Medicine position stand. Quantity and quality of exercise for developing and maintaining cardiorespiratory, musculoskeletal, and neuromotor fitness in apparently healthy adults: guidance for prescribing exercise. Med Sci Sports Exerc. 2011;43(7):1334-59.

39. Lan C, Chen SY, Lai JS. Relative exercise intensity of Tai Chi Chuan is similar in different ages and gender. Am J Chin Med. 2004;32(1):151-60.

40. Li JX, Hong Y, Chan KM. Tai chi: physiological characteristics and beneficial effects on health. Br J Sports Med. 2001:35(3):148-56.

41. Mordi I, Mordi N, Delles C, Tzemos N. Endothelial dysfunction in human essential hypertension. J Hypertens. 2016;34(8):1464-72.

42. Wang JG, Bu PL, Chen LY, Chen X, Chen YY, Cheng WL, Chu SL, Cui ZQ, Dai QY, Feng YQ, Jiang XJ, Jiang YN, Li WH, Li Y, Li Y, Lin JX, Liu J, Mu JJ, Peng YX, Song L, Sun NL, Wang Y, Xi Y, Xie LD, Xue H, Yu J, Yu W, Zhang YQ, Zhu ZM. 2019 Chinese hypertension league guidelines on home blood pressure monitoring. J Clin Hypertens (Greenwich). 2020;22(3):378-83.

43. Fang JQ. Quality of life measurement method and application. Beijing Peking University Medical Press; 2000.

44. Harris PA, Taylor R, Thielke R, Payne J, Gonzalez N, Conde JG. Research electronic data capture (REDCap) - -a metadata-driven methodology and workflow process for providing translational research informatics support. J Biomed Inform. 2009;42(2):377-81.

45. Zheng H, Li J, Li Y, Zhao L, Wu X, Chen J, Li X, Huang YL, Chang XR, Liu M, Cui J, Wang RH, Du X, Shi J, Guo TP, Liang FR. Acupuncture for patients with mild hypertension: a randomized controlled trial. J Clin Hypertens (Greenwich). 2019:21(3):412-20.

46. Gkaliagkousi E, Gavriilaki E, Triantafyllou A, Douma S. Clinical significance of endothelial dysfunction in essential hypertension. Curr Hypertens Rep. 2015; 17(11):85.

47. Davel AP, Wenceslau CF, Akamine EH, Xavier FE, Couto GK, Oliveira HT, Rossoni LV. Endothelial dysfunction in cardiovascular and endocrinemetabolic diseases: an update. Braz J Med Biol Res. 2011:44(9):920-32.

48. Konukoglu D, Uzun H. Endothelial dysfunction and hypertension. Adv Exp Med Biol. 2017:956:511-40.

49. Mancia G, Fagard R, Narkiewicz K, Redon J, Zanchetti A, Böhm M, Christiaens T, Cifkova R, De Backer G, Dominiczak A, Galderisi M, Grobbee DE, Jaarsma T, Kirchhof P, Kjeldsen SE, Laurent S, Manolis AJ, Nilsson PM Ruilope LM, Schmieder RE, Sirnes PA, Sleight P, Viigimaa M, Waeber B, Zannad F, Redon J, Dominiczak A, Narkiewicz K, Nilsson PM, Burnier M Viigimaa M, Ambrosioni E, Caufield M, Coca A, Olsen MH, Schmieder RE, Tsioufis C, van de Borne P, Zamorano JL, Achenbach S, Baumgartner H, Bax $J$ J, Bueno H, Dean V, Deaton C, Erol C, Fagard R, Ferrari R, Hasdai D, Hoes AW, Kirchhof P, Knuuti J, Kolh P, Lancellotti P, Linhart A, Nihoyannopoulos P, Piepoli MF, Ponikowski P, Sirnes PA, Tamargo JL, Tendera M, Torbicki A, Wijns W, Windecker S, Clement DL, Coca A, Gillebert TC, Tendera M, Rosei EA, Ambrosioni E, Anker SD, Bauersachs J, Hitij JB, Caulfield M, De Buyzere
M, De Geest S, Derumeaux GA, Erdine S, Farsang C, Funck-Brentano C, Gerc V, Germano G, Gielen S, Haller H, Hoes AW, Jordan J, Kahan T, Komajda M, Lovic D, Mahrholdt H, Olsen MH, Ostergren J, Parati G, Perk J, Polonia J, Popescu BA, Reiner Z, Rydén L, Sirenko Y, Stanton A, Struijker-Boudier H, Tsioufis C, van de Borne P, Vlachopoulos C, Volpe M, Wood DA. 2013 ESH/ ESC guidelines for the management of arterial hypertension: the task force for the management of arterial hypertension of the European Society of Hypertension (ESH) and of the European Society of Cardiology (ESC). Eur Heart J. 2013;34(28):2159-219.

50. Sabbahi A, Arena R, Elokda A, Phillips SA. Exercise and hypertension: uncovering the mechanisms of vascular control. Prog Cardiovasc Dis. 2016; 59(3):226-34.

51. Pescatello LS, MacDonald HV, Lamberti L, Johnson BT. Exercise for hypertension: a prescription update integrating existing recommendations with emerging research. Curr Hypertens Rep. 2015;17(11):87.

\section{Publisher's Note}

Springer Nature remains neutral with regard to jurisdictional claims in published maps and institutional affiliations.

Ready to submit your research? Choose BMC and benefit from:

- fast, convenient online submission

- thorough peer review by experienced researchers in your field

- rapid publication on acceptance

- support for research data, including large and complex data types

- gold Open Access which fosters wider collaboration and increased citations

- maximum visibility for your research: over $100 \mathrm{M}$ website views per year

At $\mathrm{BMC}$, research is always in progress.

Learn more biomedcentral.com/submissions 